\title{
Pyrohydrolysis, a clean separation method for separating non-metals directly from solid matrix
}

\begin{abstract}
Pyrohydrolysis is a sample preparation technique widely employed for the separation of fluorine, chlorine, bromine, iodine, boron and sulphur from solid samples which include refractive materials that are difficult to dissolve. There is a growing interest in the application of this technique to samples of diverse nature. Pyrohydrolysis is based on the principle that pulverization of a soild sample due to the combined action of heat and steam at high temperature produces volatile compounds of the analytes which are trapped in an alkaline solution for subsequent analysis. Studies reported in the recent past have investigated the effect of various pyrohydrolysis conditions required to pulverise the matrix as well as to convert the analytes into their volatile oxides. Hence, the physico-chemical investigation on one type of the sample is different from the other and such information is very useful while dealing with a new material for its pyrohydrolysis. This mini review is an attempt to highlight a few pyrohydrolytic separations which have significant importance.
\end{abstract}

Keywords: physico-chemical investigation, soild sample, pyrohydrolysis, thermodynamic principle, non-metals, carrier gas, halogens, sulphur, volatile compounds, fluorine, high temperature, instrumental analysis, separation technique
Volume 2 Issue 6 - 2018

\author{
Mishra VG, Jeyakumar S \\ Radioanlytical Chemistry Division, Bhabha Atomic Research \\ Centre, India
}

\begin{abstract}
Correspondence: S leyakumar, Radioanlytical Chemistry Division, Bhabha Atomic Research Centre, Mumbai 400085 , India, Email sjkumer@barc.gov.in
\end{abstract}

Received: September II, 2017 | Published: November 07 2018

\section{Introduction}

Pyrohydrolysis $(\mathrm{PH})$ is a separation technique and it is in practice prior to $1950 .{ }^{1}$ It is also known as "High temperature hydrolysis". Warf and co-workers utilised this technique for analytical purpose for the first time in $1954 .^{2}$ Since then pyrohydrolysis has been widely used for separating halogens, boron and sulphur in solid matrices especially in rocks, minerals, coals, fuels and in many biotic as well as abiotic compounds. The technique is based on the formation of volatile compounds of halogens and other non-metals due to the hydrolysis of halogens and other non-metals at high temperature. Subsequently the volatile compounds can be condensed and collected after driving out them by passing a moist carrier gas. The release of halogens is based on the following thermodynamic principle.

$M F_{2 n}+n H_{2} \mathrm{O} \leftrightarrow M O_{n}+2 n H F$

The above reaction is feasible only when the temperature is in the range of $900-1200{ }^{\circ} \mathrm{C}$ in presence of water. In practice, the solid sample taken in a quartz or silica boat is heated in a silica or quartz make reaction tube placed in a tubular furnace where a continuous flow of moist carrier gas is maintained. The carrier gas may be either air or oxygen or argon. During this process, the halides are converted into their oxides and subsequently they are converted into their respective acids. For instance, fluorine and boron are converted into $\mathrm{HF}$ and $\mathrm{H}_{3} \mathrm{BO}_{3}$, respectively. Depending upon the nature of the matrix the kinetics of pyrohydrolysis process varies. In order to improve the kinetics of pyrohydrolysis accelerators or catalysts or fluxes are mixed with the samples having slow kinetics. The commonly known accelerators or catalysts or fluxes are $\mathrm{U}_{3} \mathrm{O}_{8}{ }^{3,4} \mathrm{~V}_{2} \mathrm{O}_{5}^{5} \mathrm{WO}_{3}{ }^{6}$ and $\mathrm{SiO}_{2}{ }^{7}$ and in such case the sample to accelerator mass ratio is required to be optimised to achieve the complete recovery of analytes within the acceptable time of pyrohydrolysis. The volatile acids are condensed and trapped in a dilute alkaline trapping solution, which is more often a dilute solution of $\mathrm{NaOH}$ or $\mathrm{Na}_{2} \mathrm{CO}_{3}$. The sample solution obtained finally in the process is known as pyrohydrolysis distillate, which is free from matrix as well as contaminants. It is considered to be a clean separation as it provides a sample solution which is almost free from reagents. Pyrohydrolysis is unique owing to its capability of separating the analytes directly from the solid samples without carrying out dissolution.

Considering the advantages of pyrohydrolysis it has been used routinely for the separation of halides and boron from diverse matrices. $^{8-11}$ Depending upon the concentration of analytes in the pyrohydrolysis distillate several analytical techniques are being employed for the determination of halides and boron. In the last ten years more than 100 research papers have been reported wherein pyrohydrolysis was employed for preparing samples that are amenable to instrumental analysis. Although pyrohydrolysis is one of the simple separation techniques, its application in several fields needed to be explored in addition to the routine applications. Recently, for the first time the separation of molybdenum from uranium matrix by pyrohydrolysis was reported. Therefore, this brief review deals with some of the important applications of pyrohydrolysis reported in the recent past.

\section{Apparatus}

Since then the implementation of pyrohydrolysis for analytical purposes, the basic design of the pyrohydrolysis apparatus has not seen significant changes, however, few modifications were incorporated. The common design of the apparatus is simple and it consists of a quartz reaction tube connected at one end to an inlet for moist carrier gas and at the other end is connected to a condenser. The moist carrier gas is produced by passing a suitable gas through boiling water. Figure 1 shows a schematic diagram of a conventional pyrohydrolysis apparatus used for nuclear fuels. The apparatus has a provision to disconnect the carrier gas flow while loading the samples. For the safe handling of radioactive materials as well as for the sake of easy operations, the pyrohydrolysis apparatus was suitably modified 
(Figure 2). This modified apparatus consists of an inner reaction tube covered with an outer reaction tube and this arrangement makes the operation ease.

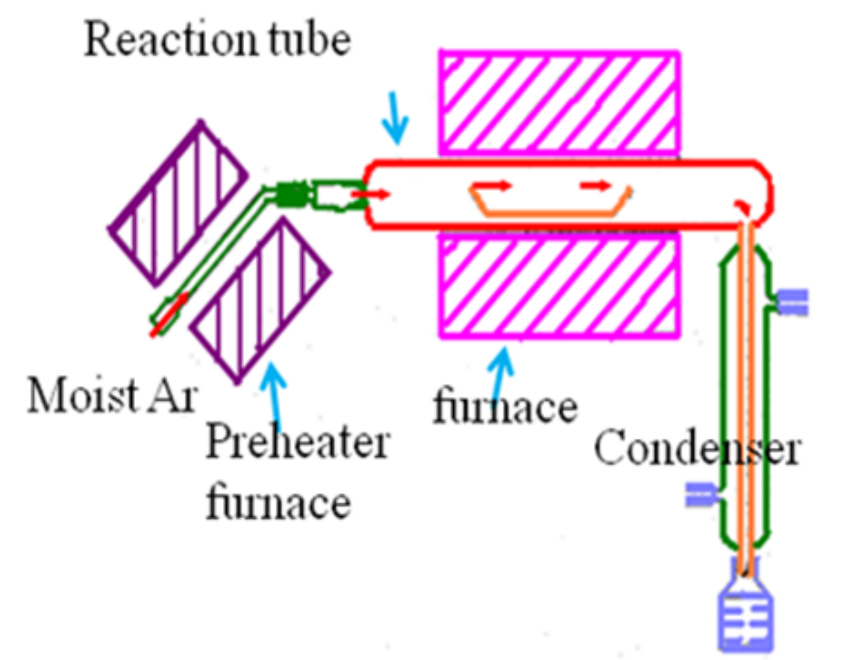

Figure I Schematic diagram of a conventional pyrohydrolysis apparatus used for nuclear fuels.

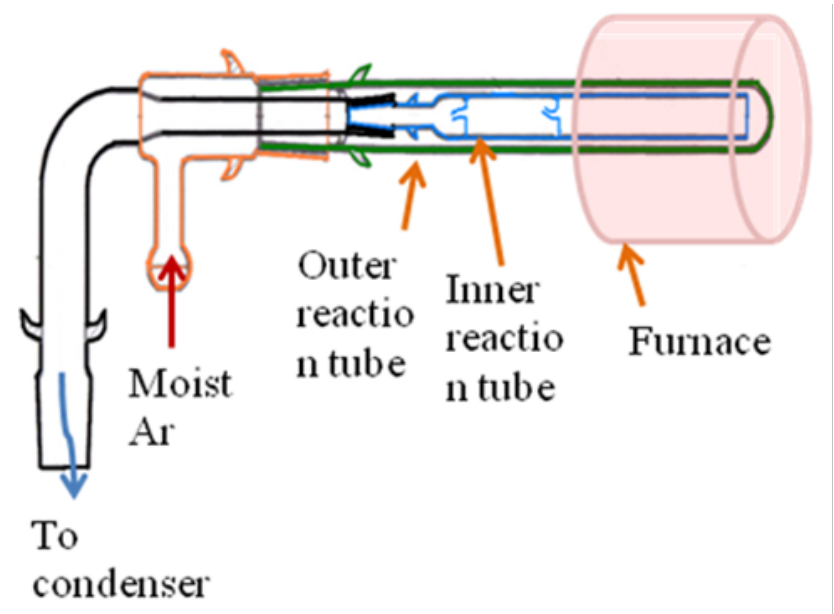

Figure 2 Schematic diagram of a modified pyrohydrolysis apparatus used for nuclear fuels.

\section{Geochemical samples}

Several analytical problems related to determination of halides, boron and sulphur in varieties of sample matrices were resolved through pyrohydrolysis method of sample preparation. Remarkable studies have been reported in halide analysis especially in coal, crude oil, nuclear materials, biological materials, geo-matrices and in minerals. Kenji S and co-workers studied the presence of fluorine, chlorine and sulphur in volcanic silicate glasses by carrying out pyrohydrolysis separation followed by their determination by ion chromatography. The crushed silicate glasses were mixed with $\mathrm{V}_{2} \mathrm{O}_{5}$ and pyrohydrolysed at $1250{ }^{\circ} \mathrm{C}$ for 30 minutes. ${ }^{12} \mathrm{M}$. Bonifacie et al. described the optimisation of chlorine extraction from silicate rocks of various mineralogy by pyrohydrolysis prior to the precise determination of $\mathrm{Cl}$ stable -isotope compositions by gas source, dual inlet Isotope Ratio Mass Spectrometry (IRMS). ${ }^{13}$ The study reported an overall $\mathrm{Cl}$ extraction yield of $100 \pm 8 \%$. Another study by Bernal et al. where the pyrohydrolytic extraction of chlorine from scapolite mineral was employed with a view to determine the stable isotopic composition of $\mathrm{Cl}$ employing isotope ratio mass spectrometry (IRMS).${ }^{14}$ Pyrohydrolysis is unique in separating halogens from the soil matrices. In many cases, pyrohydrolysis is employed as a standard technique for comparing the recoveries obtained from other methods or for carrying out analytical validation while establishing a new methodology for halogen separation and determination. Pereira et al. proposed a microwave based volatilisation technique for separating halogens from soil samples wherein pyrohydrolytic extraction of halides was employed with a view to validate the proposed method. ${ }^{15}$

Pyrohydrolysis has been used in analysing large number of geological reference materials. S. Sekimoto and M. Ebihara determined halogens $(\mathrm{Cl}, \mathrm{Br}$ and $\mathrm{I})$ by radiochemical neutron activation analysis (RNAA) and they also carried out pyrohydrolytic separation to investigate the inconsistencies observed between the RNAA results and literature values. They reported about the incomplete recovery of chlorine in pyrohydrolysis ${ }^{16}$ reported a fast and efficient pyrohydrolysis extraction method for iodine from different types of geochemical samples which include internal reference standards of soils, reference materials of bauxite, granite, tonalite, seyenite and feldspars. They investigated the effect of various fluxes such as $\mathrm{PbCrO}_{4} / \mathrm{PbO}, \mathrm{WO}_{3} /$ $\mathrm{V}_{2} \mathrm{O}_{5}$ and $\mathrm{V}_{2} \mathrm{O}_{5}$ on the pyrohydrolytic decomposition of geomaterials taken for investigation and they found that $\mathrm{V}_{2} \mathrm{O}_{5}$ is preferred among them as it provided better recovery of iodine while pyrohydrolysing the samples for about 15 minutes at $1060{ }^{\circ} \mathrm{C} .{ }^{17}$ Determination of chlorine and bromine in sedimentary and igneous rocks by alkaline fusion followed by ion chromatography detection was proposed by PA Blackwell et al. The results for chlorine were validated by comparing the values obtained from pyrohydrolysis- flow injection analysis. ${ }^{18} \mathrm{~L}$ Pagea et al. ${ }^{19}$ studied the halogen behaviour in subducting slaps and for which the halogens viz. $\mathrm{F}, \mathrm{Cl}, \mathrm{Br}$ and I were separated from the samples by pyrohydrolysis. The work provided the complete details of pyrohydrolysis. ${ }^{19}$ Fluorine content of several materials was determined using pyrohydrolysis extraction of fluorine and fluoride ion-selective electrode method to determine the sources of $\mathrm{F}$ and the pathways of causing fluorosis was reported by S Dai et al. ${ }^{20}$ In addition to the analytical applications of pyrohydrolysis for the soil and geological samples as mentioned above, there are many such studies dealing with the determination of halogens in soil samples, rock, sediment, cement samples etc. where pyrohydrolysis separation was exploited. ${ }^{21-23}$ Analysis of halides in magmatic apatites, geochemical reference materials and clay samples were also reported with pyrohydrolysis separation. ${ }^{24-28}$ Quantitative separation of halides from soil and rock samples by pyrohydrolysis is difficult and the same was shown by comparing with neutron activation analysis. ${ }^{23}$

\section{Analysis of coal}

Pyrohydrolysis has been proved to be an effective and reliable method for the separation of iodine from coal and other geological materials as it provides the sample free from matrix as well as from the excess regents added. Since coal is a combustible organic medium with significant sulphur content, it requires controlled combustion with appropriate oxygen flux to avoid deflagration as well as the formation of sulphorus acid. Daishe Wu et al. extensively studied the pyrohydrolytic decomposition of coal for separating iodine. They also studied the variables that can affect the separation and their optimum conditions were identified. ${ }^{29} \mathrm{~B}$. Peng and et al., determined F, Cl, Br, and I in coal samples by pyrohydrolysis-IC, where pyrohydrolysis conditions were optimised with a view to obtain better limit of detections (LODs) for F, Cl, Br and I. ${ }^{30}$ Sredovi 'ca et al. determined fluorine in lignite coal in order to understand the corrosion effects of $\mathrm{F}$ in thermal power plants and its environmental impact. They evaluated 
the pyrohydrolysis parameters and optimised by using two statistical approaches. further quantification of fluoride in the pyrohydrolytic distillate was carried out FISE method. ${ }^{31}$ Pyrohydrolysis separation of fluorine in super-high organic sulphur coals was also reported..$^{32} \mathrm{The} \mathrm{Br}$ and I in raw coal, bottom ash (BA) and fly ash (FA) from seven thermal power plants (TPP) were determined using pyrohydrolysis separation followed by ICP-MS analysis. ${ }^{28}$ Pyrohydrolysis is extensively used in certifying the newly developed reference materials ${ }^{33}$ and also in the determination of halogens in fossil fuels ${ }^{34}$ and petroleum samples such as crude oil. ${ }^{35}$

\section{Isotopic composition of halides}

Interesting work on the determination of isotopic compositions of halogens ( $\mathrm{I}$ and $\mathrm{Cl}$ ) were reported where pyrohydrolysis separation played an important role in obtaining a clean sample suitable for the mass spectrometric analyses. Determination of ${ }^{129} \mathrm{I} /{ }^{127} \mathrm{I}$ in fish samples has been reported and the method had an advantage of very low background. ${ }^{36}$ M. N. Herold et al., used pyrohydrolysis for a similar separation of ${ }^{129} \mathrm{I}$ and ${ }^{127} \mathrm{I}$ from organic rich soil matrix. ${ }^{37}{ }^{129} \mathrm{I}$ was determined in Fukushima and Chernobyl soil samples by following pyrohydrolysis-ICPMS method. ${ }^{38-40}$ Pyrohydrolysis was also applied for the determination of $\mathrm{Cl}$ isotopes, as $\mathrm{Cl}$ isotopes are considered as tracers for geochemical processes. ${ }^{41}$

\section{Environmental and biological samples}

Applications of pyrohydrolysis were extended to the analysis of biological and environmental samples. Pyrohydrolysis separation of $\mathrm{Br}$ and $\mathrm{I}$ in airborne particulate matters collected on a glass filter was reported. ${ }^{42}$ Another work deals with the separation of $\mathrm{Br}, \mathrm{F}$ and $\mathrm{I}$ in medicines and in some mineral supplements..$^{43}$ In both the cases quantification was achieved with ICP-MS. Determination of iodine was carried out in food materials, where the separation of iodine was investigated with a stepwise temperature conditions. ${ }^{44}$ The research articles on the pyrohydrolysis of nano particles were also reported. ${ }^{45-47}$

\section{Pyrohydrolysis in nuclear industry}

The nuclear materials like, nuclear fuels, cladding materials, neutron poisons, reflectors, control rod materials (both finished products and starting raw materials) etc. has stringent specification limits for $\mathrm{F}, \mathrm{Cl}$ and $\mathrm{B}$. For instance the maximum permissible limit of $\mathrm{Cl}$ and $\mathrm{F}$ in oxide and carbide fuels are 15 and $25 \mu \mathrm{g} / \mathrm{g}$ respectively. This is because fluorine and chlorine are corrosive elements and their presence in the above materials would initiate corrosion of both structural and fuel elements. Boron on the other hand is a neutron poison as it has high neutron cross section. Like halogens boron is also amenable to pyrohydrolysis separation. ${ }^{9}$ Pyrohydrolysis is being used on routine basis to separate halogens and boron simultaneously from nuclear materials. ${ }^{48}$ Since pyrohydrolysis has the advantage to handle the radioactive materials safely and it provides a sample solution free from radioactive matrix elements like $\mathrm{Pu}$ etc., it is widely employed for separating halogens and boron in nuclear fuels and associated materials. For example, separation of chlorine and fluorine from $\mathrm{Pu}$-alloys and $(\mathrm{U}, \mathrm{Pu}) \mathrm{C}$ samples are achieved only by pyrohydrolysis. Determination of fluoride and chloride in radioactive liquid wastes was also reported wherein the separation was carried out by pyrohydrolysis by mixing the liquid sample with a pre-analysed holding material $\left(\mathrm{U}_{3} \mathrm{O}_{8}\right.$ powder). ${ }^{49}$ Thorium oxide, an important nuclear material, is a refractory material and difficult to pyrohydrolyse. A pandey et al..$^{50}$ had studied the pyrohydrolytic behaviour of thoria using different accelerators $\left(\mathrm{V}_{2} \mathrm{O}_{5}, \mathrm{WO}_{3}\right.$ and $\left.\mathrm{MoO}_{3}\right)$. An application of $\mathrm{x}$-ray fluorescence method for determining chlorine in pyrohydrolytic distillate of $(\mathrm{U}, \mathrm{Pu}) \mathrm{C}$ has been reported..$^{51}$

Metallic fuels such as $\mathrm{U}-\mathrm{Zr}$ and $\mathrm{U}-\mathrm{Pu}-\mathrm{Zr}$ alloys are the proposed fuels for the fast breeder reactors and determination of halogens in these fuels also carried out by pyrohydrolytic separation. The study also showed in addition to the pyrohydrolisability, the matrix opening is also a crucial factor for achieving the complete recovery of halogens. ${ }^{52}$ An ion chromatographic study deals with the separation and identification of pyrohydrolysis products of $(\mathrm{U}, \mathrm{Pu}) \mathrm{C}$ has been reported $^{53}$ and the study further reported that the pyrohydrolytic conditions are responsible for the formation of organic acids during the pyrohydrolysis of metal carbides. Another study reports about the pyrohydrolytic separation of boron in $\mathrm{U}_{3} \mathrm{Si}_{2}$ required for the determination of isotopic composition of boron by ICP-MS. ${ }^{54}$ Pyrohydrolysis was used for generation of zirconia from $\mathrm{ZrF}_{4}{ }^{55}$ Jia Peng et al., studied the pyrohydrolysis behaviour of $\mathrm{SmF}_{3}$ with a view to address the issues related to thorium based molten salt reactor fuels. ${ }^{56}$ Recently feasibility on the pyrohydrolytic separation of molybdenum as its volatile oxide has been explored for the first time. Mo present in a matrix can be oxidised to its oxide $\mathrm{MoO}_{3}$ (with high vapour pressure), further the vapour pressure of the oxide increases drastically in presence of moist environment. Based on these observations, a novel method of pyrohydrolysis for separating Mo from uranium matrix was established.$^{57}$ The study describes about the necessary conditions for pyrohydrolysis and the modifications incorporated in the pyrohydrolysis apparatus for achieving complete recovery of Mo.

\section{Miscellaneous applications}

Apart from above applications, pyrohydrolysis has been used to separate halogens from cardboard ${ }^{58}$ and iron ore. ${ }^{59}$ It was also used for regeneration of spent pickling solution. ${ }^{60}$ During steel production $\mathrm{HCl}$ is used to remove the oxide layer on the surface and this pickling solution after use was regenerated using pyrohydrolysis. S Zhou et al. have shown the use of pyrohydrolysis to generate $\mathrm{HCl}$ from $\mathrm{NaCl}$ for chlorination of nickel and iron oxides ${ }^{61}$ Pyrohydrolysis was applied in the determination of halogens in glass reference materials (BHVO2G, BIR-1G, BCR-2G, GSD-1G, GSE-1G, NIST SRM 610 and NIST SRM 612). ${ }^{62}$ In the determination of halides in glass standards the pyrohydrolysis distilates were analysed by Ion Chromatography and $\mathrm{X}$-ray fluoresence techniques.

\section{Conclusion}

Pyrohydrolysis is widely used for the separation of halogens, sulphur and boron directly from different types of samples. It provides a sample solution free from matrix and therefore, considered to be a clean separation method. Although it is known as an old methodology, its scope gets expanded every year due to its applications in diverse fields.

\section{Acknowledgements}

None.

\section{Conflict of interest}

The author declares there is no conflict of interest.

\section{References}

1. Rickard RR, Ball FL, Harris WW. Microdetermination of Fluorine in Solid Halocarbons. Anal Chem. 1951;23(6):919-921. 
2. Ware JC, Cline WD, Tevebaugh RD. Pyrohydrolysis in Determination of Fluoride and Other Halides. Anal Chem. 1954;26(2):342-346.

3. Adams PB, Williams JP. Fluoride Analysis of Glasses and Silicate Materials by Pyrohydrolysis Separation. $J$ Am Ceram Soc. 1958;41(9):377-380.

4. Banks CV, Burke KE, O'Laughlin JW. The determination of fluorine in rare earth fluorides by high temperature hydrolysis. Anal Chim Acta. 1958;19(C):239-243.

5. Nebesar B. The high-temperature analytical uses of vanadium (V) oxide. Talanta. 1978;25(4):185-194.

6. Nardozzi MJ, Lewis LL. Pyrolytic Separation and Determination of Fluoride in Raw Materials. Anal Chem. 1961;33(9):1261-1264.

7. Itoh $\mathrm{M}$, Watanabe $\mathrm{K}$, Hatakeyama $\mathrm{M}$, et al. Determination of ${ }^{36} \mathrm{Cl}$ in biological shield concrete using pyrohydrolysis and liquid scintillation counting. Analyst. 2002;127(7):964-966.

8. Wiederkehr VR, Goward GW. Separation of Boron from Alloys and Other Materials by Pyrohydrolysis. Anal Chem. 1959;31(12): 21022103.

9. Morgan L. The determination of boron by a pyrohydrolysis technique. Analyst. 1964;89(1062):621-623.

10. Newman ACD. A simple apparatus for separating fluorine from aluminosilicates by pyrohydrolysis. The Analyst. 1968;93(1113):827831 .

11. Troll G, Farzaneh A. Determination of Fluorine and Total Water in ThirtyThree International Geochemical Reference Samples. Geostandards Newsletter. 1978;2(1):43-47.

12. Shimizu K, Ushikubo T, Hamada M, et al. $\mathrm{H}_{2} \mathrm{O}, \mathrm{CO}_{2}, \mathrm{~F}, \mathrm{~S}, \mathrm{Cl}$, and $\mathrm{P}_{2} \mathrm{O}_{5}$ analyses of silicate glasses using SIMS: Report of volatile standard glasses. Geochem J. 2017;51(4):299-313.

13. Bonifacie M, Jendrzejewski N, Agrinier P, et al. PyrohydrolysisIRMS determination of silicate chlorine stable isotope compositions Application to oceanic crust and meteorite samples. Chemical Geology. 2007;24(1-2):187-201.

14. Bernal NF, Gleeson SA, Smith MP, et al. Evidence of multiple halogen sources in scapolites from iron oxide-copper-gold (IOCG) deposits and regional $\mathrm{NaCl}$ metasomatic alteration, Norrbotten County, Sweden. Chemical Geology. 2017;451(20):90-103.

15. Pereira LSF, Pedrotti MF, Enders MSP, et al. Multitechnique Determination of Halogens in Soil after Selective Volatilization Using Microwave-Induced Combustion. Anal Chem. 2017;89(1):980-987.

16. Sekimoto S, Ebihara M. Accurate Determination of Chlorine, Bromine and Iodine in U.S. Geological Survey Geochemical Reference Materials by Radiochemical Neutron Activation Analysis. Geostand Geoanal Res. 2017;41(2):213-219.

17. Rae JE, Malik SA. The determination of iodine in geochemical samples: the use of pyrohydrolytic decomposition. Chemosphere. 1996;33(11):2121-2128.

18. Blackwell PA, Cave MR, Davis AE, et al. Determination of chlorine and bromine in rocks by alkaline fusion with ion chromatography detection. J Chrom A. 1997;770:93-98.

19. Pagé L, Hattori K, Hoog JCM. Halogen (F, Cl, Br, I) behaviour in subducting slabs: A study of lawsonite blueschists in western Turkey. Earth Planet Sci Lett. 2016;442:133-142.

20. Dai S, Li W, Tang Y, et al. The sources, pathway, and preventive measures for fluorosis in Zhijin County, Guizhou, China. Appl Geochem. 2007;22(5):1017-1024.

21. Shimizu K, Suzuki K, Saitoh M, et al. Simultaneous determinations of fluorine, chlorine, and sulfur in rock samples by ion chromatography combined with pyrohydrolysis. Geochem J. 2015;1 49(1):113-124.
22. Duarte FA, Pereira ER, Flores ELM, et al. Spectrophotometric determination of chloride in cement after sample preparation by pyrohydrolysis. Quimica Nova. 2001;36(5):716-719.

23. Sekimoto S, Ebihara M. Accurate determination of chlorine, bromine, and iodine in sedimentary rock reference samples by radiochemical neutron activation analysis and a detailed comparison with inductively coupled plasma mass spectrometry literature data. Anal Chem. 2013;85(13):6336-6341.

24. Bing-Xian P, Dai-She W. Simultaneous rapid determination of halogens in clay using pyrohydrolysis combined with ion chromatography. J Anal Chem. 2013;41(10):1499-1504.

25. Marks MAW, Wenzel T, Whitehouse MJ, et al. The volatile inventory (F, Cl, Br, S, C) of magmatic apatite: An integrated analytical approach. Chem Geology. 2013;291:241-255.

26. Takeda A, Yamasaki S, Tsukada H, et al. Determination of total contents of bromine, iodine and several trace elements in soil by polarizing energy-dispersive X-ray fluorescence spectrometry. Soil Science and Plant Nutrition. 2011;57(1):19-28.

27. Balcone-Boissard H, Michel A, Villemant B. Simultaneous determination of fluorine, chlorine, bromine and iodine in six geochemical reference materials using pyrohydrolysis, ion chromatography and inductively coupled plasma-mass spectrometry. Geostand and Geoanal Res. 2009;33(4):477-485.

28. Peng B, Li L, Wu D. Distribution of bromine and iodine in thermal power plant. J Coal Sci Eng. 2013;19(3):387-391.

29. Wua D, Deng H, Wang W. Catalytic spectrometric determination of iodine in coal by pyrohydrolysis decomposition. Anal Chim Act. 2003;601:183-188.

30. Peng B, Wu D, Lai J, et al. Simultaneous determination of halogens ( $\mathrm{F}, \mathrm{Cl}, \mathrm{Br}$, and $\mathrm{I})$ in coal using pyrohydrolysis combined with ion chromatography. Fuel. 2002;94:629-631.

31. Sredovi'c I, Rajakovi'c Lj. Pyrohydrolytic determination of fluorine in coal: A chemometric approach. J Hazard Mater. 2009;177: 445-451.

32. Xie P, Guo W, Yan X, et al. Fluorine in Lopingian superhigh-organicsulfur coals from the Lalang Coal Mine, Guangxi, southern China. Fuel. 2017;208:483-490

33. Tanaka $\mathrm{T}$, Inoba $\mathrm{S}$, Kawada $\mathrm{S}$, et al. Development of coal ash certified reference materials JSAC 0521 and 0522 for determination of inorganic constituents. Bunseki Kagaku. 2010;59(2):137-150.

34. Antes FG, Duarte FA, Flores ELM, et al. Fluoride and chloride determination in fossil fuels after sample preparation by pyrohydrolysis. Quimica Nova. 2010;33(5):1130.

35. Antes FG, Dos Santos MDFP, Loureno Guimarães RC, et al. Heavy crude oil sample preparation by pyrohydrolysis for further chlorine determination. Anal Methods. 2011; 3(2):288-293.

36. Kusuno H, Matsuzaki H, Nagata T. An approach for measuring the ${ }^{129} \mathrm{I} /{ }^{127} \mathrm{I}$ ratio in fish samples. Nucl Instrum Methods in Phys Res Sect. 2015;361:414-418.

37. Herod MN, Cornett RJ, Clark ID. Extraction of ${ }^{129} \mathrm{I}$ and ${ }^{127} \mathrm{I}$ via combustion from organic rich samples using ${ }^{125} \mathrm{I}$ as a quantitative tracer. Environ Radio. 2014;138:323-330.

38. Ohno T, Muramatsu Y, Shikamori Y, et al. Determination of ultratrace ${ }^{129} \mathrm{I}$ in soil samples by Triple Quadrupole ICP-MS and its application to Fukushima soil samples. J Anal Atom Spectrom. 2013;28(8):1283-1287.

39. Sahoo SK, Muramatsu Y, Yoshida S, et al. Determination of ${ }^{129} I$ and ${ }^{127} I$ concentration in soil samples from the chernobyl $30-\mathrm{km}$ zone by AMS and ICP-MS. J Radiat Res. 2009;50(4):325-332.

40. Muramatsu Y, Takada Y, Matsuzaki H, et al. AMS analysis of ${ }^{129} \mathrm{I}$ in Japanese soil samples collected from background areas far from nuclear facilities. Quat Geochron. 2008;3(3):291-297. 
41. Fietzke J, Frische M, Hansteen TH, et al. A simplified procedure for the determination of stable chlorine isotope ratios $(837 \mathrm{Cl})$ using LA-MCICP-MS. J Anal Atom Spectrom. 2008;23(5):769-772.

42. Picoloto RS, Cruz SM, Mello PA, et al. Combining pyrohydrolysis and ICP-MS for bromine and iodine determination in airborne particulate matter. Microchem J. 2014;116:225-229.

43. Taflik T, Duarte FA, Flores ELM, et al. Determination of bromine, fluorine and iodine in mineral supplements using pyrohydrolysis for sample preparation. J Braz Chem Soc. 2012;23(3):488-495.

44. Shinoda T, Miyamoto N, Kuromoto T, et al. Pyrohydrolysis Coupled to Ion Chromatography for Sensitive Determination of Iodine in FoodRelated Materials. Anal Lett. 2012;45(8):862-871.

45. Antes FG, Pereira JSF, Enders MSP, Flores EMM, Dressler VL. Pyrohydrolysis of carbon nanotubes for $\mathrm{Br}$ and I determination by ICPMS. Microchem J. 2012;101:54-58.

46. Antes FG, Pereira JSF, Spadoa LC, et al. Fluoride determination in carbon nanotubes by ion selective electrode. J tBraz Chem Soc. 2012;23(6):1193-1198.

47. Feng L, Li Y, Su X, et al. Growth and characterization of spindle-like $\mathrm{Ga}_{2} \mathrm{O}_{3}$ nanocrystals by electrochemical reaction in hydrofluoric solution. Appl Surf Sci. 2016;389:205-210.

48. Jeyakumar S, Raut VV, Ramakumar KL. Simultaneous determination of trace amounts of borate, chloride and fluoride in nuclear fuels employing ion chromatography (IC) after their extraction by pyrohydrolysis. Talanta. 2008;76(5):1246-1251.

49. Sawant RM, Mahajan MA, Shah DJ. Pyrohydrolytic separation technique for fluoride and chloride from radioactive liquid wastes. $J$ Radioanal Nucl Chem. 2011;287(2):423-426.

50. Pandey A, Kelkar A, Singhal RK, et al. Effect of accelerators on thoria based nuclear fuels for rapid and quantitative pyrohydrolytic extraction of $\mathrm{F}^{-}$and $\mathrm{Cl}^{-}$and their simultaneous determination by ion chromatography. $J$ Radioanal Nucl Chem. 2012;293(3):743-749.

51. Dhara S, Misra NL, Thakur UK, et al. A total reflection X-ray fluorescence method for the determination of chlorine at trace levels in nuclear materials without sample dissolution. X-Ray Spectrom. 2012;41(5):316-320.

52. Mishra VG, Sali SK, Shah DJ, et al. Studies on U-Zr and U-Pu-Zr alloys for determination of $\mathrm{Cl}$ and $\mathrm{F}$ using pyrohydrolysis. Radiochim Acta. 2014;102(10):895-901.
53. Jeyakumar S, Mishra VG, Das MK, et al. Study on the identification of organic and common anions in the pyrohydrolysis distillate of mixed uranium-plutonium carbide for the interference free determination of chlorine and fluorine by ion chromatography. Radiochim Acta. 2014;102(4):291-302.

54. Saha A, Shah D, Deb SB, et al. Simultaneous quantification and isotope ratio measurement of boron in uranium-silicon-aluminium compounds by inductively coupled plasma orthogonal acceleration time of flight mass spectrometry (ICP-oa-TOFMS) after its separation by pyrohydrolysis. Microchem. J. 2015;121:56-64.

55. Goncharuk V, Starodubtsev P, Maslennikova I. Synthesis of microdispersed zirconium oxide for glass manufacturing. IOP Conference Series: Materials Science and Engineering. 2016;112(1):12-31.

56. Peng J, Zheng X, Qiu T, et al. Pyrohydrolysis of $\mathrm{SmF} 3$ in moist air. $J$ Fluorine Chem. 2017;193:106-112.

57. Mishra VG, Thakur UK, Shah DJ, et al. Direct Separation of Molybdenum from Solid Uranium Matrices Employing Pyrohydrolysis, a Green Separation Method, and Its Determination by Ion Chromatography. Anal Chem. 2015;87(21):1072-1073.

58. Hofmann NR, Paniz JNG, Flores EMDM, Pedrotti MF, Dressler VL, (2016) Determination of Halogens in Cardboard Gaskets Using Pyrohydrolysis. Anal Lett. 49(12) 1903-1916.

59. Li YN, Xu ZB, Zhang ZW. Determination of fluorine and chlorine in iron ores by pyrohydrolysis-ion chromatography. Metall Analysis. 2016;36(6):23-28.

60. Bascone D, Cipollina A, Morreale M, et al. Simulation of a regeneration plant for spent pickling solutions via spray roasting. Desalin Water Treat. 2016;57(48-49):23405-23419.

61. Zhou S, Wei YLB, Ma B, et al. Mechanism of sodium chloride in promoting reduction of high-magnesium low-nickel oxide ore. Scientific Reports. 2016;6:29061.

62. Marks MAW, Kendrick MA, Eby GN. The $\mathrm{F}, \mathrm{Cl}, \mathrm{Br}$ and I Contents of Reference Glasses BHVO-2G, BIR-1G, BCR-2G, GSD-1G, GSE$1 \mathrm{G}$, NIST SRM 610 and NIST SRM 612. Geostand. Geoanall Res. 2017;41(1):107-122. 